\title{
Genetic homogeneity among Leishmania (Leishmania) infantum isolates from dog and human samples in Belo Horizonte Metropolitan Area (BHMA), Minas Gerais, Brazil
}

\author{
Thais Almeida Marques da Silva ${ }^{1,2}$, Luciana Inácia Gomes ${ }^{1}$, Edward Oliveira', Wendel Coura-Vital ${ }^{1,3,4}$, \\ Letícia de Azevedo Silva ${ }^{6}$, Fabiano Sviatopolk-Mirsky Pais ${ }^{5}$, Henrique Gama Ker ${ }^{4}$, Alexandre Barbosa Reis ${ }^{4}$, \\ Ana Rabello ${ }^{1}$ and Mariangela Carneiro ${ }^{2,3^{*}}$
}

\begin{abstract}
Background: Certain municipalities in the Belo Horizonte Metropolitan Area (BHMA), Minas Gerais, Brazil, have the highest human visceral leishmaniasis (VL) mortality rates in the country and also demonstrate high canine seropositivity. In Brazil, the etiologic agent of VL is Leishmania (Leishmania) infantum. The aim of this study was to evaluate the intraspecific genetic variability of parasites from humans and from dogs with different clinical forms of VL in five municipalities of BHMA using PCR-RFLP and two target genes: kinetoplast DNA (kDNA) and gp63.

Methods: In total, 45 samples of DNA extracted from clinical samples $(n=35)$ or L. infantum culture $(n=10)$ were evaluated. These samples originated from three groups: adults (with or without Leishmania/HIV co-infection; $n=14$ ), children $(n=18)$ and dogs $(n=13)$. The samples were amplified for the kDNA target using the MC1 and MC2 primers (447 bp), while the Sg1 and Sg2 (1330 bp) primers were used for the gp63 glycoprotein target gene.

Results: The restriction enzyme patterns of all the samples tested were monomorphic.

Conclusions: These findings reveal a high degree of genetic homogeneity for the evaluated gene targets among L. infantum samples isolated from different hosts and representing different clinical forms of VL in the municipalities of BHMA studied.
\end{abstract}

Keywords: Leishmania (Leishmania) infantum, Intraspecific genetic variability, PCR-RFLP

\section{Background}

Leishmaniasis is among the six endemic diseases considered to be priority diseases worldwide and is characterized by its great diversity and complexity [1]. Approximately 1.3 million new cases of leishmaniasis are estimated to occur annually, and of these cases, 300,000 correspond to visceral leishmaniasis $(\mathrm{VL})$. VL is considered the most severe form of the disease, and it is potentially fatal if left untreated.

\footnotetext{
* Correspondence: mcarnei@@icb.ufmg.br

²Laboratório de Epidemiologia das Doenças Infecciosas e Parasitárias,

Departamento de Parasitologia, Instituto de Ciências Biológicas, Universidade Federal de Minas Gerais, Belo Horizonte, Minas Gerais, Brasil

${ }^{3}$ Pós-graduação em Ciências da Saúde: Infectologia e Medicina Tropical, Faculdade de Medicina, Universidade Federal de Minas Gerais, Belo

Horizonte, Minas Gerais, Brasil

Full list of author information is available at the end of the article
}

Between 20,000 and 40,000 people are estimated to die of VL worldwide annually $[2,3]$.

In Brazil, VL is caused by Leishmania (Leishmania) infantum [synonym of Leishmania (Leishmania) chagasi], which is an obligate intracellular protozoan belonging to the Leishmania donovani complex [4]. In the urban context, domestic dogs are the main reservoir of this parasite, and the sandfly Lutzomyia (Lutzomyia) longipalpis is the main vector of the disease [5].

Between 2005 and 2011, the mean incidence rate of VL in Brazil was approximately 2.0 cases per 100,000 inhabitants, and the mortality rate was $6.7 \%$ [6]. Certain municipalities in the Belo Horizonte Metropolitan Area (BHMA) have had high mortality rates, including Belo Horizonte, where rates ranged from $8.2 \%$ in 2007 to 
$21.8 \%$ in 2012 , with a mean rate of $17.1 \%$ [7]. In several studies conducted in BHMA municipalities, L. infantum infection rates ranged from $2.4 \%$ to $18.1 \%$, depending on the population studied or the diagnostic technique used [8-10].

Several studies have been conducted to examine the intraspecific genetic variability between $L$. infantum strains and their possible association with different types of hosts [11,12], different geographical origins [13-15], parasite transmission dynamics [16] and the spread of the disease [16-19]. For these purposes, various molecular approaches have been used: (i) randomly amplified polymorphic DNA (RAPD) [14,20,21]; (ii) analysis of DNA regions using multilocus microsatellite typing (MLMT) [13,22]; (iii) simple sequence repeat (SSR)-PCR [14,23]; (iv) analysis using DNA hybridization probes (Southern blotting) [24] and (v) restriction fragment length polymorphism (RFLP) analysis [11,25-28]. Although the BHMA comprises municipalities with high human mortality rates, asymptomatic infection and canine prevalence, few studies have been conducted in this area to evaluate whether genetic variability exists among isolates from different hosts and clinical forms of VL $[12,29]$. Consequently, the aim of this study was to evaluate the genetic variability of $L$. infantum in humans (children and adults with or without Leishmania/HIV co-infection) and in dogs with different clinical forms of VL (symptomatic, oligosymptomatic and asymptomatic) in BHMA municipalities.

\section{Methods}

\section{Study samples}

Thirty-five clinical samples (whole blood, $\mathrm{n}=12$; bone marrow aspirate, $\mathrm{n}=15$; and spleen biopsy, $\mathrm{n}=8$ ) and $10 \mathrm{~L}$. infantum culture samples from human and canine $\mathrm{VL}$ cases were used. The samples originated from three groups: VL-symptomatic children $(\mathrm{n}=18)$, VLsymptomatic adults $(\mathrm{n}=14)$ and dogs with different clinical forms of VL (symptomatic, oligosymptomatic and asymptomatic) $(\mathrm{n}=13)$ (Table 1$)$.

The sex distribution was equal in the group of children (nine females and nine males), with a mean age of 4.5 years old $(\mathrm{SD}=2.2)$. In the adult group, 11 patients were men, and three were women; the mean age was 38.7 years old $(\mathrm{SD}=11)$. Among the adults, 10 individuals had Leishmania/HIV co-infection (Table 1).

The human samples (children and adults) were obtained at the cryobank of the Laboratory of Clinical Research, Centro de Pesquisas René Rachou. The canine samples originated from the cryobank of the Laboratory of Clinical Research, Federal University of OuroPreto.

The 45 evaluated DNA samples were selected from VL cases that occurred between the years 2010 to 2012, in five municipalities in the state of Minas Gerais belonging to the BHMA: Belo Horizonte $(\mathrm{n}=32,19$ human cases
Table 1 Characteristics of the evaluated samples

\begin{tabular}{|c|c|c|c|}
\hline \multicolumn{2}{|l|}{ Variables } & $\begin{array}{l}\text { Humam } \\
\text { n (\%) }\end{array}$ & \multirow{2}{*}{$\begin{array}{l}\text { Dogs } \\
\text { n (\%) } \\
7(538)\end{array}$} \\
\hline \multirow[t]{2}{*}{ Sex } & Female & $12(37.5)$ & \\
\hline & Male & $20(62.5)$ & $6(46.2)$ \\
\hline \multirow[t]{5}{*}{ City } & Belo Horizonte & $19(59.4)$ & $13(100)$ \\
\hline & Contagem & $5(15.6)$ & 0 \\
\hline & Ribeirão das Neves & $4(12.5)$ & 0 \\
\hline & Betim & $1(3.1)$ & 0 \\
\hline & Ibirité & $3(9.4)$ & 0 \\
\hline \multirow[t]{2}{*}{ HIV } & Positive & $10(31.2)$ & Not applicable \\
\hline & Negative & $22(68.8)$ & Not applicable \\
\hline \multirow[t]{4}{*}{ Sample } & Bone marrow aspirate & $15(46.9)$ & 0 \\
\hline & Culture sample & $5(15.6)$ & $5(38.5)$ \\
\hline & Whole bood & $12(37.5)$ & 0 \\
\hline & Spleen biopsy & 0 & $8(61.5)$ \\
\hline \multirow[t]{3}{*}{ Clinical form } & Asymptomatic & 0 & $4(30.8)$ \\
\hline & Oligosymptomatic & 0 & $6(46.1)$ \\
\hline & Symptomatic & $32(100)$ & $3(23.1)$ \\
\hline \multirow[t]{2}{*}{ Collection } & LPC/CPqRR & $32(100)$ & 0 \\
\hline & LPC/UFOP & 0 & $13(100)$ \\
\hline \multirow[t]{3}{*}{ Year isolation } & 2010 & $1(3.1)$ & $13(100)$ \\
\hline & 2011 & $20(62.5)$ & 0 \\
\hline & 2012 & $11(34.4)$ & 0 \\
\hline
\end{tabular}

LPC/CPqRR, Laboratório de Pesquisas Clínicas, Centro de Pesquisas René Rachou. LPC/UFOP, Laboratório de Pesquisas Clínicas, Universidade Federal de Ouro Preto.

and 13 canine cases), Betim ( $\mathrm{n}=1$ human case), Contagem ( $\mathrm{n}=5$ human cases), Ibirité ( $\mathrm{n}=3$ human cases) and Ribeirão das Neves ( $\mathrm{n}=4$ human cases). All 45 samples were initially analyzed by the PCR-RFLP molecular technique [30] to characterize the samples as $L$. infantum. In addition to being subjected to molecular analyses, the Leishmania culture samples were classified at the species level according to the multi-locus enzyme electrophoresis (MLEE) technique, following the protocol established by Cupolillo et al. [31], performed in the Leishmania Collection of the Oswaldo Cruz Institute.

\section{Promastigote culture}

Leishmania infantum promastigote culture aliquots were isolated by bone marrow aspiration from humans and dogs. These samples were cultured in liver infusion tryptose (LIT) culture medium supplemented with $20 \%$ inactivated fetal bovine serum and blood-NNN medium (bacteriological agar with defibrinated rabbit blood), for approximately 45 days. Thus, it was possible to obtain a large enough volume for culture aliquots that were then employed in the isoenzyme analysis using the MLEE technique and in the molecular analysis, the latter of 
which occurred after the extraction of the genomic DNA.

\section{DNA extraction}

Total DNA obtained from the clinical samples and the genomic DNA of the L. infantum cultures were extracted using the DNA QIAamp DNA Mini Kit (QIAGEN GmbH, Hilden, Germany), according to the manufacturer's instructions. Negative controls for the DNA extraction process were used in all assays. The DNA extraction yield was determined by reading the absorbance at $260 \mathrm{~nm}$ in a Nanodrop ND-1000 (Thermo Fisher Scientific, Wilmington, DE, USA) spectrophotometer. The $\mathrm{A}_{260} / \mathrm{A}_{280}$ absorbance ratio was assessed to verify the purity of the obtained DNA.

\section{Polymerase chain reaction}

In this study, two genomic targets from L. infantum were used for the PCR, namely, the kinetoplast DNA (kDNA) minicircle region and the gp63 glycoproteinencoding gene.

The specific reaction for the kDNA minicircle region was performed according to Cortes et al. [32], with some modifications. The primers used were MC1 (5'-GTTAGCCGATGGTGGTCTTG-3') and MC2 (5'-CACCCATTTTTCCGATTTTG-3'), which amplify a sequence of 447 base pairs (bp). The reaction was prepared in a final volume of $100 \mu \mathrm{L}$, containing 5-10 $\mu \mathrm{L}$ of DNA (enough volume to contain 50 ng of DNA), 3 U of Platinum Taq DNA Polymerase (Invitrogen, São Paulo, Brazil), 1X PCR buffer (200 mMTris- $\mathrm{HCl}, \mathrm{pH}$ 8.4, $500 \mathrm{mMKCl}$; Invitrogen), $0.6 \mu \mathrm{M}$ each primer, $2 \mathrm{mM} \mathrm{MgCl}_{2}$ and $0.4 \mathrm{mMdNTPs}$ (Promega, Madison, WI, USA). The thermal cycling program consisted of an initial step of 2 minutes at $94^{\circ} \mathrm{C}$, followed by 35 cycles at $94^{\circ} \mathrm{C}$ for 20 seconds, $58^{\circ} \mathrm{C}$ for 20 seconds and $72^{\circ} \mathrm{C}$ for 30 seconds. A final extension step at $72^{\circ} \mathrm{C}$ for 5 minutes was also included.

The specific PCR for the gp63 glycoprotein-encoding gene was performed according to Guerbouj et al. [26], with some modifications. The primers used were SG1 (5'-GTCTCCACCGAGGACCTCACCGA-3') and SG2 (5'-TGATGTAGCCGCCCTCCTCGAAG-3'), which amplify a 1330 -bp sequence. The reaction was prepared in a final volume of $40 \mu \mathrm{L}$, containing approximately $4 \mu \mathrm{L}$ of DNA (enough volume to contain $30 \mathrm{ng}$ of DNA), 1.5 $\mathrm{U}$ of Platinum Taq DNA Polymerase (Invitrogen), 1X PCR buffer (200 mMTris- $\mathrm{HCl}, \mathrm{pH} 8.4,500 \mathrm{mMKCl}$; Invitrogen), $0.6 \mu \mathrm{M}$ of each primer, $1.5 \mathrm{mM} \mathrm{MgCl}_{2}$ and $0.2 \mathrm{mMdNTPs}$ (Promega). The thermal cycling program consisted of an initial step at $94^{\circ} \mathrm{C}$ for 4 minutes and
35 cycles at $94^{\circ} \mathrm{C}$ for 1 minute, $67^{\circ} \mathrm{C}$ for 1 minute and $72^{\circ} \mathrm{C}$ for 1 minute, as well as a final extension step at $72^{\circ} \mathrm{C}$ for 8 minutes.

The amplification products were visualized in a $6 \%$ polyacrylamide gel after staining with $0.2 \%$ silver nitrate.

All assays included negative PCR controls (PCR mix without DNA), negative DNA extraction controls (PCR mix with the negative DNA extraction control) and positive PCR controls (DNA extracted from $L$. infantum promastigotes from the MHOM/BR/2002/LPC-RPV reference sample).

\section{Restriction fragment length polymorphism}

Five of the six main endonucleases used by Cortes et al. [28] (VspI, DdeI, BglII, HpaII and RsaI; Promega) were employed to digest the 447-bp kDNA fragment. Two endonucleases were used for the digestion of the 1330-bp fragment of the gp63 glycoprotein-encoding gene; i.e., HincII (according to Guerbouj et al. [26], with some modifications) and TaqI (according to Quispe-Tintaya et al. [27], Botilde et al. [21], Seridi et al. [33], with some modifications) (Promega).

The digestion reactions were performed separately for each enzyme in a final volume of $20 \mu \mathrm{L}$. All reactions contained $15 \mu \mathrm{L}$ of the amplification product, $5 \mathrm{U}$ of restriction enzyme, $1 \mathrm{X}$ buffer specific for each enzyme and $1 \mu \mathrm{g}$ of bovine serum albumin. All enzyme reactions, except for that of $\mathrm{TaqI}$, were incubated at $37^{\circ} \mathrm{C}$ for 3 hours and 30 minutes, followed by 10 minutes at $65^{\circ} \mathrm{C}$, as recommended by the manufacturer. The reactions with the TaqI enzyme were incubated at $65^{\circ} \mathrm{C}$ for 3 hours and 30 minutes.

The products obtained from the restriction enzyme reactions were visualized on a polyacrylamide gel after staining with $6 \%$ ethidium bromide $(0.5 \mathrm{mg} / \mathrm{mL})$ and were photographed in an L-Pix EX gel documentation system (Loccus Biotechnology, Cotia, SP, Brazil).

The reference strains (Table 2) were also subjected to PCR-RFLP for comparison with the analyzed samples.

The gel images were analyzed with the GelAnalyzer 2010 software (available at http://www.gelanalyzer.com). To more accurately determine the length of the fragments, a sample of each group was randomly selected $(n=7)$ and submitted to capillary electrophoresis in the Bioanalyzer 2100 device (Agilent Technologies GmbH, Waldbronn, Germany).

\section{Analysis of nucleotide sequences deposited in GenBank and subsequent in silico analysis in the RestrictionMapper program}

The BLAST algorithm (http://blast.ncbi.nlm.nih.gov/ Blast.cgi) was used to search for specific nucleotide sequences corresponding to the kDNA and gp63 gene targets. For this purpose, the primer sequences $\mathrm{MC1}$ and 
Table 2 Strains used for a reference pattern

\begin{tabular}{lll}
\hline Identification & Species & International code \\
\hline Reference strain \#1 (Ref 1) & Leishmania (Leishmania) infantum & MHOM/BR/2002/LPC-RPV \\
Reference strain \#2 (Ref 2) & Leishmania (Leishmania) infantum & MHOM/BR/1974/PP75 \\
Reference strain \#3 (Ref 3) & Leishmania (Leishmania) donovani & MHOM/ET/1967/HU3 \\
Reference strain \#4 (Ref 4) & Leishmania (Leishmania) amazonensis & IFLA/BR/1967/PH-8 \\
Reference strain \#5 (Ref 5) & Leishmania (Viannia) braziliensis & MHOM/BR/75/M2903 \\
\hline
\end{tabular}

$\mathrm{MC} 2$ were used in the search, as were the previously described SG1 and SG2 primers. Only sequences that met the quality parameter with a high degree of identity (approximately 100\%) with the primers and the Leishmania organism were selected. Seven sequences for the kDNA target and five sequences for the gp63 target were analyzed. The sequences selected from GenBank originate from $L$. infantum or $L$. donovani samples isolated in different African and Central American countries, as well as in European countries (Table 3).

Subsequently, these nucleotide sequences were analyzed through in silico digestion in the RestrictionMapper version program (available at http://www.restrictionmapper.org), with the same enzyme panel as that used in the laboratory experiments. After restriction, the program generated the exact length of the obtained fragments. These sequences were compared to the study samples to infer phylogenetic relationships.

\section{Phylogenetic analysis for the kDNA minicircle region}

To analyze the phylogenetic relationships, the restriction patterns resulting from the cleavage of the PCR products by the endonucleases were used to determine profiles or genotypes and were interpreted through qualitative analysis. The 45 samples of this study were phylogenetically compared to the 129 described by Cortes et al. [28]

Table 3 Nucleotide sequences selected from GenBank

\begin{tabular}{llll}
\hline Target & Identification & Species & Accession no./Country of origin \\
\hline kDNA & GenBank1 & L. infantum & AF169140.1/Tunisia \\
& GenBank2 & L. infantum & AF169133.1/Algeria \\
& GenBank3 & L. infantum & AF103741.1/Tunisia \\
& GenBank4 & L. infantum & AF169131.1/Portugal \\
& GenBank5 & L. infantum & AF103740.1/United Kingdom ${ }^{a}$ \\
& GenBank6 & L. donovani & AJ010077.2/Sudan \\
GenBank7 & L. chagasi & AF169137.1/Panama \\
gp63 GenBank8 & L. infantum & Y08156.1/France \\
& GenBank9 & L. infantum & U48798.1/Spain \\
& GenBank10 & L. donovani & AJ495003.1/Kenya \\
GenBank11 & L. donovani & AJ495006.1//raq \\
GenBank12 & L. donovani & AJ495004.1/China \\
\hline
\end{tabular}

${ }^{\mathrm{a}}$ For this sequence of nucleotides, the patient was most probably infected in Spain (associated paper PUBMED: 10413058). (classified as genotypes A to O) as well as to the seven samples previously selected in GenBank and three reference strains (Ref 1,2 and 3) forming a database with a total of 184 samples. The genotypes identified in this study were named according to Cortes et al. [28]. Restriction patterns from all samples were inserted into a binary matrix, with the fragments coded as present (1) or absent (0). The SplitsTree4 software was used for the construction of a crosslinked network (Figure 1) [34,35].

The crosslinked network is more appropriate than the bifurcated phylogenetic tree to describe the complex relationship populations because it shows conflicts in a data set, without prior assumptions of the causes of these conflicts [36].

\section{Ethical considerations}

This study was approved by the Research Ethics Committee of the Federal University of Minas Gerais, in a collaborative study with Centro de Pesquisas René Rachou/FIOCRUZ and Federal University of OuroPreto (CAEE-03904112.0.0000.5149). In addition, the canine samples collection was approved by the Committees of Ethics in Animal Experimentation of the Universidade Federal de Ouro Preto protocol no. 083/2007), of the Universidade Federal de Minas Gerais (protocol no. 020/ 2007), and of the City Council of Belo Horizonte (protocol no. 001/2008). All procedures in dogs in this study were according to the guidelines set by the Brazilian Animal Experimental Collage (COBEA), Federal Law number 11794.

\section{Results}

All 45 DNA samples analyzed in this study showed PCR amplification of the kDNA gene fragment (447-bp), specific for the Leishmania donovani complex, and the gp63 gene fragment (1330-bp), specific for trypanosomatids.

The PCR assay for the kDNA target showed a detection limit of $1 \mathrm{pg}$ of genomic DNA (1:10 serial dilution) of the L. infantum reference sample (MHOM/BR/2002/ LPC-RPV), while the detection limit was $10.42 \mathrm{fg}$ for the gp63 target.

The PCR-RFLP analysis of both targets (i.e., kDNA and gp63) in the 45 DNA samples analyzed revealed the genetic homogeneity of $L$. infantum. Thus, for each analyzed endonuclease, a single enzyme restriction pattern 


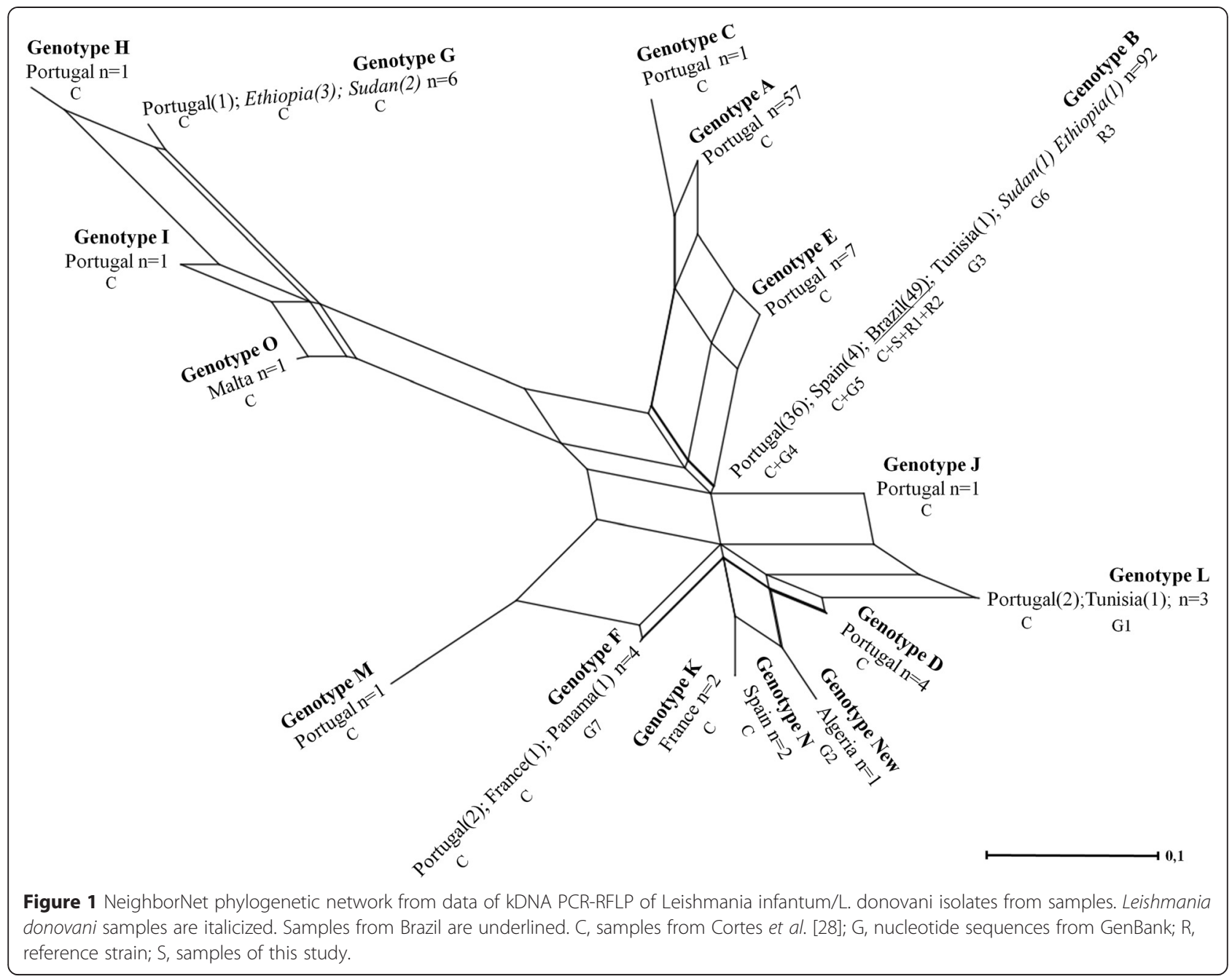

was observed (Table 4). However, there was some variability between the nucleotide sequences obtained after searching GenBank (Table 3) and the subsequent in silico analysis in the RestrictionMapper program.

Table 4 Restriction enzyme patterns obtained with PCR-RFLP

\begin{tabular}{|c|c|c|c|c|c|c|c|}
\hline \multirow{2}{*}{$\begin{array}{l}\text { Targets } \\
\text { Endonucleases }\end{array}$} & \multicolumn{5}{|l|}{ kDNA } & \multicolumn{2}{|l|}{ gp63 } \\
\hline & $V_{s p l^{a}}$ & $\overline{D d e l^{a}}$ & $B g / I^{a}$ & $\mathrm{Hpall}^{\mathrm{a}}$ & $\left.R s a\right|^{a}$ & Hincll $^{b}$ & $\overline{\text { Taql }}$ \\
\hline \multirow[t]{8}{*}{ Fragments (bp) } & 161 & 319 & 447 & 410 & 253 & 1250 & 504 \\
\hline & 152 & 100 & & $37^{c}$ & 194 & 850 & 414 \\
\hline & 134 & $28^{c}$ & & & & 400 & 180 \\
\hline & & & & & & 80 & 84 \\
\hline & & & & & & & 80 \\
\hline & & & & & & & $29^{c}$ \\
\hline & & & & & & & $22^{c}$ \\
\hline & & & & & & & $20^{c}$ \\
\hline
\end{tabular}

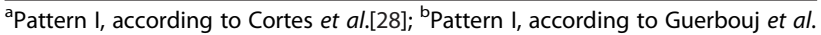
[26]; ${ }^{\mathrm{C}}$ Fragments lost during electrophoresis.
PCR-RFLP for the kDNA minicircle region

After restriction enzyme analysis by PCR-RFLP of the kDNA minicircle region (447-bp), the following patterns were found in the 45 DNA analyzed samples: the $V s p$ I enzyme produced 134-, 152- and 161-bp fragments; the DdeI enzyme produced 28-, 100- and 319-bp fragments; and the BglII enzyme produced only one 447-bp fragment; that is, the fragment remained intact, with no specific restriction site for this enzyme in the sequence. These patterns were also observed in all seven nucleotide sequences for the kDNA target obtained after searching the GenBank (GenBank 1,2,3,4,5,6 and 7) and subsequent in silico analysis in the RestrictionMapper program and in the reference strains $\mathrm{MHOM} / \mathrm{BR} / 2002$ / LPC-RPV (Ref1), MHOM/BR/1974/PP75 (Ref2) and MHOM/ET/1967/HU3 (Ref3). All of these patterns for the analyzed enzymes are similar to that described by Cortes et al. [28], known as Pattern I.

For the enzyme HpaII, 37- and 410-bp fragments were observed for all 45 DNA samples evaluated. This same pattern was observed in the reference strains: Ref1, Ref2 
and Ref3, and in four nucleotide sequences for the kDNA target: GenBank 3, 4, 5 and 6. This pattern is known as Pattern I, according to Cortes et al. [28]. Three of the seven nucleotide sequences obtained after the GenBank search and subsequent in silico analysis in the RestrictionMapper program showed genetic variability: AF169140.1/GenBank1-kDNA (Tunisia/North Africa), AF169133.1/GenBank2-kDNA (Algeria/North Africa) and AF169137.1/Genbank7-kDNA (Panama/Central America). The first nucleotide sequence (AF169140.1/Genbank1kDNA) produced 37-, 123- and 287-bp fragments, considered by Cortes et al. [28] as Pattern II for the HpaII enzyme. The second nucleotide sequence (AF169133.1/ GenBank2-kDNA) produced 123- and 324-bp fragments, not yet described in the literature. Finally, the last nucleotide sequence (AF169137.1/Genbank7-kDNA) produced 37-, 60- and 350-bp fragments, described by Cortes et al. [28] as Pattern IV.

The analysis using the RsaI enzyme revealed a single pattern with 194- and 253-bp fragments for the 45 DNA samples analyzed in this study, as well as for the reference strains (Ref1, Ref2 and Ref3) and six nucleotide sequences: GenBank 2, 3, 4, 5, 6 and 7. This pattern was described as Pattern I, according to Cortes et al. [28]. The AF169140.1/GenBank1-kDNA nucleotide sequence exhibited variability, including 48-, 146- and 253-bp fragments, the same pattern described by Cortes et al. [28] as Pattern IV for the RsaI enzyme.

\section{Phylogenetic analysis - minicircleregion kDNA}

The phylogenetic analysis for samples tested by PCRRFLP for the target kDNA showed that all 45 samples analyzed as well as reference samples 1 and 2 were within the Genotype B described by Cortes et al. [28] (Figure 1). The two samples of Brazilian origin used by Cortes et al. [28] were also included in the same genotype. Samples from Portugal (36), Spain (4), Tunisia (1) Sudan (1) and Ethiopia (1) were also included in this genotype. The latter two samples are L.donovani, GenBank6 and Ref3, respectively. The other samples are L.infantum.

It was observed that within the cluster in which the genotype B is inserted, samples of genotype A, C and E from Portugal were also included.

The other genotypes (D, F, G, H, I, J, K, L, M, N, O, and new) were located in other phylogenetic network clusters and include samples from different countries. The genotypes $G$ and $B$ were the only samples with another species, L.donovani. In genotype $\mathrm{G}$, three of these samples were from Ethiopia and one from Sudan. A different genotype was identified, not described in the literature, and was named "New Genotype." This was a sample obtained from GenBank (GenBank2) from Algeria.

\section{PCR-RFLP for the gp63 glycoprotein-encoding gene}

Analysis with the HincII enzyme produced a single pattern with four fragments, 80-, 400-, 850- and 1250-bp, for the 45 DNA samples analyzed, the reference strains (Ref1, Ref2 and Ref 3 ) and all five nucleotide sequences: GenBank 8, 9, 10, 11 and 12 (Table 3). The 80- and 1250-bp bands were clearer and exhibited better resolution than the 400- and 850-bp bands. Pattern I was also described by Guerbouj et al. [26] for the HincII enzyme.

With the TaqI enzyme, only one pattern, Pattern I, could be identified, with five fragments: 80-, 84-, 180-, 414- and 504-bp. Several authors have used the PCR-RFLP technique to analyze the gp63 glycoprotein-encoding gene using the restriction endonuclease TaqI; however, the fragment patterns produced were not clearly shown in those studies $[21,27,33]$. Thus, it was not possible to perform phylogenetic analysis for the target gp63.

Pattern I found in the 45 DNA samples analyzed in this study (80-, 84-, 180-, 414- and 504-bp fragments) can be compared to the nucleotide sequences for the gp63 target obtained after searching GenBank and subsequent in silico analysis in the RestrictionMapper program. The same pattern was obtained for the nucleotide sequence U48798.1/GenBank9-gp63. This sequence also exhibited 20-, 22- and 29-bp bands that could not be visualized in the $(6 \%)$ polyacrylamide gels analyzed in this study, due to the low molecular weight and losses during electrophoresis.

\section{Discussion}

The present study evaluated the intraspecific genetic variability of $L$. infantum in human and canine VL cases from BHMA through the use of PCR-RFLP and different target genes: the gp63 glycoprotein-encoding gene and minicircle region of $\mathrm{kDNA}$. The analysis showed genotypic homogeneity in the studied samples, with regard to all tested endonucleases for the target genes. However, some nucleotide sequences from GenBank and from $L$. infantum or L. donovani specimens isolated in different African, Central American, and European countries showed genotypic variability. One of the strains from GenBank (GenBank2) demonstrated a band profile not described in the literature, which we named New Genotype in this work. These findings show that the methodology chosen for this study was effective for evaluating the intraspecific genetic variability of L. infantum, considering its relationship with geographical origin in different countries, which gives even greater strength to the results obtained with the Brazilian samples.

In addition to the $45 \mathrm{~L}$. infantum DNA samples evaluated by PCR-RFLP, two other DNA samples extracted from $L$. infantum cultures of two VL-symptomatic patient samples were included in the study by convenience 
sampling (data not shown). These samples originated from the Minas Novas and Aimorés municipalities, which are approximately $516 \mathrm{~km}$ and $456 \mathrm{~km}$ from Belo Horizonte, respectively. Even with the inclusion of those samples from municipalities that are not part of the BHMA, genetic homogeneity was consistent among the targets evaluated in the study samples.

Other studies conducted in Brazil, in general, also found low genetic variability among the studied samples $[12,15,16,18,29]$. Specifically, Segatto et al. [14] evaluated the genetic variability of $L$. infantum in samples from different regions of Brazil and also found no differences between human and dog samples. Chicharro et al. [37] obtained similar results using the RAPD and intergenic region typing of the ribosomal RNA internal transcribed spacer region techniques, finding no genotypic differences between Leishmania isolates from dogs and humans of Majorca Island, Spain.

It is important to note that this is the first study that simultaneously evaluates two targets (kDNA and gp63) using both samples from humans (children and adults with or without Leishmania/HIV co-infection) and from dogs with different clinical forms of VL (symptomatic, oligosymptomatic and asymptomatic) to monitor $L$. infantum population spread at RMBH.

The kDNA was one of the selected targets because minicircles are useful targets for evaluating genetic variability due to their involvement in a rapid response to different environmental conditions and physiological stress situations [11,28]. This characteristic most likely interferes with the adaptability of the parasite, which may acquire selective advantages in accordance with the most prevalent minicircle class within the kDNA network [11,38]. The other selected target was the gp63 glycoprotein because it is a very important protein in the virulence of the parasite, and the gene is under constant selective pressure in the phase of the parasite's adaptation; therefore, the protein is a promising target for the study of genetic variability in Leishmania [26,39].

Several molecular approaches have been used to study genetic variability of parasites of the genus Leishmania, but in most studies, MLMT [13] and RFLP [11] have proven to be the best tools for analyzing population genetics and epidemiological data. In this study, PCR-RFLP was used because, in addition to the technique's high sensitivity, ease of execution and good reproducibility of the results obtained, it allows a refined distinction between parasite strains through the identification of polymorphisms in the specific restriction sites for the evaluated endonucleases [28,33].

Phylogenetic analyses indicated great genetic variability among the samples from Portugal because these were present in almost all genotypes found. However, a greater number of Portuguese samples were concentrated in two genotypes: A (57 samples) and B (36 samples). The B genotype also accounted for all Brazilian samples (49) analyzed: 45 samples from the metropolitan region of Belo Horizonte, two samples of Cortes et al. [28] and two samples used as reference L.infantum (Ref1 and Ref2). These data indicate that infection by L.infantum (genotype B) is common in both Brazil and Portugal. The results found in the present study corroborate the hypothesis of the introduction of L. infantum in South America, through the great sea voyages that took place approximately 500 years ago $[4,18,40]$. Those studies concluded that 500 years is a relatively short time to generate genetic variability, especially in Brazil, where VL has one main vector (L. longipalpis) and the $\operatorname{dog}$ (Canis familiaris) as the main reservoir. However, to confirm this hypothesis, genotyping samples from other geographical regions of Brazil is necessary in view of the disease's large territorial range.

Moreover, prior studies also took into consideration that the prevalent reproduction mode of species of the genus Leishmania is clonal; i.e., their genotypes can be used as reliable epidemiological markers, thus facilitating the study of the dispersal of this parasite [41,42]. Although genetic recombination has been recorded by some authors for the genus Leishmania [43-45], this phenomenon is still considered a rare event.

\section{Conclusion}

In our work, we showed that no genetic variability occurred between the different evaluated groups, considering the different types of hosts (dogs and humans), as well as the various clinical forms of VL in dogs and distinct aspects related to age, sex and the presence or absence of Leishmania/HIV co-infection in humans. Our results suggest that only one L. infantum strain is circulating in human and canine populations in BHMA. However, other studies should be done in BHMA with a larger number of different host samples (human, dogs and phlebotomine sand fly), and additional molecular techniques should be used to provide a more complete picture of the $L$. infantum genetic variability in the region and to complement our results.

\footnotetext{
Abbreviations

BHMA: Belo Horizonte Metropolitan Area; kDNA: kinetoplast DNA; MLEE: Multi-locus enzyme electrophoresis; MLMT: Multilocus microsatellite typing; PCR: Polymerase chain reaction; RFLP: Restriction fragment length polymorphism; SSR: Simple sequence repeat; VL: Visceral leishmaniasis.

Competing interests

The authors declare that they have no competing interests.

\section{Authors' contributions}

Conceived and designed the experiments: TAMS, LIG, EO and MC. Performed the experiments: TAMS, LIG, HGK and EO. Analyzed the data: TAMS, LIG, EO, MC. Contributed in obtaining biological samples: AR, ABR, WCV and HGK. Contributed to phylogenetic analysis: FSMP and LAS. All authors contributed to the manuscript preparation. All authors read and approved the final version of the manuscript.
} 


\section{Acknowledgements}

This study was supported by the following grants: PNPD/Institutional/2011, PPSUS/MS/CNPq/FAPEMIG/SES-MG/grant CBB-APQ-00356-10; CNPQ/Universal 478528/2012-4 and FAPEMIG/PPM. The funders had no role in study design, data collection or analysis, decision to publish, or preparation of the manuscript. $M C, A R, A B R$, LAS and EO are grateful for CNPq fellowships. WCV is grateful to the PNPD/CAPES fellowships. TAMS is grateful for CAPES fellowships during her master's degree.

\section{Author details}

'Laboratório de Pesquisas Clínicas, Centro de Pesquisas René Rachou, Fundação Oswaldo Cruz, Belo Horizonte, Minas Gerais, Brasil. 'Laboratório de Epidemiologia das Doenças Infecciosas e Parasitárias, Departamento de Parasitologia, Instituto de Ciências Biológicas, Universidade Federal de Minas Gerais, Belo Horizonte, Minas Gerais, Brasil. Pós-graduação em Ciências da Saúde: Infectologia e Medicina Tropical, Faculdade de Medicina, Universidade Federal de Minas Gerais, Belo Horizonte, Minas Gerais, Brasil. ${ }^{4}$ Laboratório de Pesquisas Clínicas, Escola de Farmácia, Universidade Federal de Ouro Preto, Ouro Preto, Minas Gerais, Brasil. ${ }^{5}$ Grupo de Genômica e Biologia Computacional, Centro de Pesquisas René Rachou, Fundação Oswaldo Cruz, Belo Horizonte, Minas Gerais, Brasil. 'aboratório de Toxoplasmose, Departamento de Parasitologia, Instituto de Ciências Biológicas, Universidade Federal de Minas Gerais, Belo Horizonte, Minas Gerais, Brasil.

Received: 30 January 2015 Accepted: 31 March 2015 Published online: 15 April 2015

\section{References}

1. World Health Organization. Working to overcome the global impact of neglected tropical diseases:First WHO report on neglected tropical diseases. WHO: Geneva: World Health Organization; 2010. p. 184. 184

2. Alvar J, Velez ID, Bern C, Herrero M, Desjeux P, Cano J, et al. Leishmaniasis worldwide and global estimates of its incidence. PLoS One. 2012;7(5), e35671.

3. WHO. World Health Organization - Sustaining the drive to overcome the global impact of neglected tropical diseases / Leishmaniasis. Available: http://www.who.int/neglected_diseases. Accessed 2013 December 12. . 2013.

4. Mauricio IL, Howard MK, Stothard JR, Miles MA. Genomic diversity in the Leishmania donovani complex. Parasitology. 1999;119(Pt 3):237-46.

5. Lainson R, Rangel EF. Lutzomyia longipalpis and the eco-epidemiology of American visceral leishmaniasis, with particular reference to Brazil: a review. Mem Inst Oswaldo Cruz. 2005;100(8):811-27.

6. Sistema de Informação de Agravos de Notificação - Sinan Net. [http:// dtr2004.saude.gov.br/sinanweb/tabnet/tabnet?sinannet/leishvi/bases/ leishvbrnet.def ].

7. PBH. Índice de Vulnerabilidade à Saúde. Secretaria Municipal de Saúde, Gerência de Epidemiologia e Informação. 10 pp. Available: http:// portalpbh.pbh.gov.br/pbh/ecp/

comunidade.do?evento=portlet\&pldPIc=ecpTaxonomia

MenuPortal\&app=saude\&lang=pt_BR\&pg $=5571 \&$ tax $=35177$. Accessed 2014 January 5. 2014.

8. Moreno EC, Melo MN, Lambertucci JR, Serufo JC, Andrade AS, Antunes CM, et al. Diagnosing human asymptomatic visceral leishmaniasis in an urban area of the State of Minas Gerais, using serological and molecular biology techniques. Rev Soc Bras Med Trop. 2006;39(5):421-7.

9. de Gouvea Viana L, de Assis TS, Orsini M, da Silva AR, de Souza GF, Caligiorne $\mathrm{R}$, et al. Combined diagnostic methods identify a remarkable proportion of asymptomatic Leishmania (Leishmania) chagasi carriers who present modulated cytokine profiles. Trans R Soc Trop Med Hyg. 2008;102(6):548-55.

10. dos Santos Marques LH, Gomes LI, da Rocha IC, da Silva TA, Oliveira E, Morais $\mathrm{MH}$, et al. Low parasite load estimated by $\mathrm{qPCR}$ in a cohort of children living in urban area endemic for visceral leishmaniasis in Brazil. PLoS Negl Trop Dis. 2012:6(12), e1955.

11. Alonso DP, Costa DL, de Mendonca IL, Costa CH, Ribolla PE. Heterogeneity of Leishmania infantum chagasi kinetoplast DNA in Teresina (Brazil). Am J Trop Med Hyg. 2010;82(5):819-21.

12. Alvarenga JS, Ligeiro CM, Gontijo CM, Cortes S, Campino L, Vago AR, et al. KDNA genetic signatures obtained by LSSP-PCR analysis of Leishmania
(Leishmania) infantum isolated from the new and the old world. PLoS One 2012;7(8), e43363.

13. Ochsenreither S, Kuhls K, Schaar M, Presber W, Schonian G. Multilocus microsatellite typing as a new tool for discrimination of Leishmania infantum MON-1 strains. J Clin Microbiol. 2006;44(2):495-503.

14. Segatto M, Ribeiro LS, Costa DL, Costa CH, Oliveira MR, Carvalho SF, et al. Genetic diversity of Leishmania infantum field populations from Brazil. Mem Inst Oswaldo Cruz. 2012;107(1):39-47.

15. Batista LF, Segatto M, Guedes CE, Sousa RS, Rodrigues CA, Brazuna JC, et al. An assessment of the genetic diversity of Leishmania infantum isolates from infected dogs in Brazil. Am J Trop Med Hyg. 2012;86(5):799-806.

16. Ferreira GE, dos Santos BN, Dorval ME, Ramos TP, Porrozzi R, Peixoto AA et al. The genetic structure of Leishmania infantum populations in Brazil and its possible association with the transmission cycle of visceral leishmaniasis. PLoS One. 2012;7(5), e36242.

17. Kuhls K, Keilonat L, Ochsenreither S, Schaar M, Schweynoch C, Presber W, et al. Multilocus microsatellite typing (MLMT) reveals genetically isolated populations between and within the main endemic regions of visceral leishmaniasis. Microbes Infect. 2007;9(3):334-43.

18. Kuhls K, Alam MZ, Cupolillo E, Ferreira GE, Mauricio IL, Oddone R, et al. Comparative microsatellite typing of new world Leishmania infantum reveals low heterogeneity among populations and its recent old world origin. PLoS Negl Trop Dis. 2011;5(6), e1155.

19. Motoie G, Ferreira GE, Cupolillo E, Canavez F, Pereira-Chioccola VL. Spatial distribution and population genetics of Leishmania infantum genotypes in Sao Paulo State, Brazil, employing multilocus microsatellite typing directly in dog infected tissues. Infect Genet Evol. 2013;18:48-59.

20. Toledo A, Martin-Sanchez J, Pesson B, Sanchiz-Marin C, Morillas-Marquez F. Genetic variability within the species Leishmania infantum by RAPD. A lack of correlation with zymodeme structure. Mol Biochem Parasitol. 2002;119(2):257-64.

21. Botilde Y, Laurent T, Quispe Tintaya W, Chicharro C, Canavate C, Cruz I, et al. Comparison of molecular markers for strain typing of Leishmania infantum. Infect Genet Evol. 2006;6(6):440-6.

22. Schwenkenbecher JM, Frohlich C, Gehre F, Schnur LF, Schonian G. Evolution and conservation of microsatellite markers for Leishmania tropica. Infect Genet Evol. 2004;4(2):99-105.

23. Oliveira RP, Macedo AM, Chiari E, Pena SD. An alternative approach to evaluating the intraspecific genetic variability of parasites. Parasitol Today. 1997;13(5):196-200.

24. Sreenivas G, Raju BV, Singh R, Selvapandiyan A, Duncan R, Sarkar D, et al. DNA polymorphism assay distinguishes isolates of Leishmania donovani that cause kala-azar from those that cause post-kala-azar dermal Leishmaniasis in humans. J Clin Microbiol. 2004;42(4):1739-41.

25. Mauricio IL, Gaunt MW, Stothard JR, Miles MA. Genetic typing and phylogeny of the Leishmania donovani complex by restriction analysis of PCR amplified gp63 intergenic regions. Parasitology. 2001;122(Pt 4):393-403.

26. Guerbouj S, Victoir K, Guizani I, Seridi N, Nuwayri-Salti N, Belkaid M, et al. Gp63 gene polymorphism and population structure of Leishmania donovani complex: influence of the host selection pressure? Parasitology. 2001;122 Pt 1:25-35.

27. Quispe Tintaya KW, Ying X, Dedet JP, Rijal S, De Bolle X, Dujardin JC. Antigen genes for molecular epidemiology of leishmaniasis: polymorphism of cysteine proteinase B and surface metalloprotease glycoprotein 63 in the Leishmania donovani complex. J Infect Dis. 2004;189(6):1035-43.

28. Cortes S, Mauricio I, Almeida A, Cristovao JM, Pratlong F, Dedet JP, et al. Application of kDNA as a molecular marker to analyse Leishmania infantum diversity in Portugal. Parasitol Int. 2006;55(4):277-83.

29. Coutinho CE, Santos DO, Baptista C, Figueiredo FB, Madeira Mde F. Evaluation of Leishmania (Leishmania) chagasi strains isolated from dogs originating from two visceral leishmaniasis-endemic areas in Brazil using multilocus enzyme electrophoresis. Rev Soc Bras Med Trop. 2011;44(5):572-5.

30. Volpini AC, Passos VM, Oliveira GC, Romanha AJ. PCR-RFLP to identify Leishmania (Viannia) braziliensis and L. (Leishmania) amazonensis causing American cutaneous leishmaniasis. Acta Trop. 2004;90(1):31-7.

31. Cupolillo E, Grimaldi Jr G, Momen H. A general classification of New World Leishmania using numerical zymotaxonomy. Am J Trop Med Hyg. 1994;50(3):296-311.

32. Cortes S, Rolao N, Ramada J, Campino L. PCR as a rapid and sensitive tool in the diagnosis of human and canine leishmaniasis using Leishmania donovani s.l.-specific kinetoplastid primers. Trans R Soc Trop Med Hyg. 2004;98(1):12-7. 
33. Seridi N, Belkaid M, Quispe-Tintaya W, Zidane C, Dujardin JC. Application of PCR-RFLP for the exploration of the molecular diversity of Leishmania infantum in Algeria. Trans R Soc Trop Med Hyg. 2008;102(6):556-63.

34. Huson DH. SplitsTree: analyzing and visualizing evolutionary data. Bioinformatics. 1998;14(1):68-73.

35. Huson DH, Bryant D. Application of phylogenetic networks in evolutionary studies. Mol Biol Evol. 2006;23(2):254-67.

36. Morrison DA. Networks in phylogenetic analysis: new tools for population biology. Int J Parasitol. 2005;35(5):567-82.

37. Chicharro C, Morales MA, Serra T, Ares M, Salas A, Alvar J. Molecular epidemiology of Leishmania infantum on the island of Majorca: a comparison of phenotypic and genotypic tools. Trans R Soc Trop Med Hyg. 2002;96 Suppl 1:S93-9.

38. Telleria J, Lafay B, Virreira M, Barnabe C, Tibayrenc M, Svoboda M. Trypanosoma cruzi: sequence analysis of the variable region of kinetoplast minicircles. Exp Parasitol. 2006;114(4):279-88.

39. Elamin EM, Guizani I, Guerbouj S, Gramiccia M, El Hassan AM, Di Muccio T, et al. Identification of Leishmania donovani as a cause of cutaneous leishmaniasis in Sudan. Trans R Soc Trop Med Hyg. 2008;102(1):54-7.

40. Lukes J, Mauricio IL, Schonian G, Dujardin JC, Soteriadou K, Dedet JP, et al. Evolutionary and geographical history of the Leishmania donovani complex with a revision of current taxonomy. Proc Natl Acad Sci U S A. 2007;104(22):9375-80.

41. Tibayrenc M, Ayala FJ. Evolutionary genetics of Trypanosoma and Leishmania. Microbes Infect. 1999;1(6):465-72.

42. Kuhls K, Chicharro C, Canavate C, Cortes S, Campino L, Haralambous C, et al. Differentiation and gene flow among European populations of Leishmania infantum MON-1. PLoS Negl Trop Dis. 2008;2(7), e261.

43. Dujardin JC, Banuls AL, Llanos-Cuentas A, Alvarez E, DeDoncker S, Jacquet $D$, et al. Putative Leishmania hybrids in the Eastern Andean valley of Huanuco. Peru Acta Trop. 1995;59(4):293-307.

44. Banuls AL, Hide M, Tibayrenc M. Molecular epidemiology and evolutionary genetics of Leishmania parasites. Int J Parasitol. 1999;29(8):1137-47.

45. Akopyants NS, Kimblin N, Secundino N, Patrick R, Peters N, Lawyer $P$, et al. Demonstration of genetic exchange during cyclical development of Leishmania in the sand fly vector. Science. 2009:324(5924):265-8.

\section{Submit your next manuscript to BioMed Central and take full advantage of:}

- Convenient online submission

- Thorough peer review

- No space constraints or color figure charges

- Immediate publication on acceptance

- Inclusion in PubMed, CAS, Scopus and Google Scholar

- Research which is freely available for redistribution 